\title{
Clinical Features of Bacteremia Caused by Methicillin-Resistant Staphylococcus aureus in a Tertiary Hospital
}

\author{
Koichi Yamada, ${ }^{1,2}$ Katsunori Yanagihara, ${ }^{1,2}$ Yukiko Hara, ${ }^{1}$ Nobuko Araki, ${ }^{1}$ \\ Yousuke Harada, ${ }^{1}$ Yoshitomo Morinaga, ${ }^{2}$ Junichi Matsuda, ${ }^{1}$ Koichi Izumikawa, ${ }^{2}$ \\ Masafumi Seki, ${ }^{2}$ Hiroshi Kakeya, ${ }^{2}$ Yoshihiro Yamamoto, ${ }^{2}$ Shigeru Kohno ${ }^{2,3}$ and \\ Shimeru Kamihira ${ }^{1}$ \\ ${ }^{1}$ Department of Laboratory Medicine, Nagasaki University Graduate School of Biomedical Sciences, Nagasaki, \\ Japan \\ ${ }^{2}$ Second Department of Internal Medicine Nagasaki University Graduate School of Biomedical Sciences, \\ Nagasaki, Japan \\ ${ }^{3}$ Global COE Program, Nagasaki University, Nagasaki, Japan
}

Methicillin-resistant Staphylococcus aureus (MRSA) has become a leading cause of infections in both the community and in hospitals. MRSA bacteremia is a serious infection with a very high mortality rate. The aim of this study was to assess the clinical features of MRSA bacteremia and to evaluate predictors of mortality in patients with this infection. The medical records of 83 patients with MRSA bacteremia, who had been admitted to Nagasaki University Hospital between January 2003 and December 2007, were retrospectively reviewed. Underlying disease, presumed source, MRSA sensitivity, Staphylococcal cassette chromosome mec (SCCmec) types, virulence genes and prognosis were evaluated. Of the 83 patients (44 men and 39 women; mean age: 63.7 years) with MRSA bacteremia, $30(36.1 \%)$ had malignancy and 25 $(30.1 \%)$ had been treated with immunosuppressive drugs. Fifteen patients $(18.1 \%)$ were intravascular catheter related. SCCmec typell accounted for $80 \%$ of SCCmec types of MRSA isolates. The mortality rate was $39.8 \%$ (33/83), which is similar to that of previous reports. The ratio of males to females, the mean age or the body temperature did not differ between survivors and nonsurvivors. Independent predictors associated with mortality in the multivariate analyses are pneumonia $(P=0.016)$, treatment with $\operatorname{VCM}(P=0.039)$, and transplantation $(P=0.021)$. We suggest that poor prognosis achieved with VCM is in part due to its low blood concentration and poor tissue penetration. VCM should not be selected when presumed source of MRSA bacteremia is pneumonia.

Keywords: methicillin-resistant Staphylococcus aureus; bacteremia; pneumonia; vancomycin; immunosuppressive Tohoku J. Exp. Med., 2011, 224 (1), 61-67. C 2011 Tohoku University Medical Press

Methicillin-resistant Staphylococcus aureus (MRSA) infections are responsible for a large proportion of infections in the community and in hospitals. Bacteremia caused by MRSA is one of the most serious problems among infectious diseases, not only because of its increasing frequency, but also because of its refractoriness to treatment and its associated high mortality rate (Selvey et al. 2000). Since 1960, when resistance of Staphylococcus aureus to methicillin was first reported, the percentage of MRSA isolates has been increasing. In Japan, the reported rate of patients with Staphylococcus aureus bacteremia continues to rise (Mizushima et al. 1994). The percentage of MRSA bacteremia comprises as high as $20 \%$ of all cases of bacteremia in US hospitals (Wisplinghhoff et al. 2004), and is about $31 \%$ of the cases in Spanish hospitals. This percentage can reach $44 \%$ when hospitalized intensive care unit patients are analyzed (Tiemersma et al. 2004). Even with adequate antibiotic therapy, the morbidity and mortality of MRSA bacteremia is reportedly higher than that of methicillin-sensitive Staphylococcus aureus bacteremia (Cosgrove et al. 2003). The mortality rate of MRSA bacteremia has been reported to be approximately 30-40\% (Gould 2007; Gomez et al. 2007; Laupland et al. 2008). Thus, early diagnosis and appropriate antibiotic therapy for bacteremia is very important. Rapid and appropriate antibiotic therapy may improve the outcome of patients with bacteremia (Leibovici et al. 1998).

The purpose of the present study was to assess the clinical and genetic characteristics of patients with MRSA bacteremia and to identify prognostic factors significantly associated with mortality.

Received January 20, 2011; revision accepted for publication April 14, 2011. doi: 10.1620/tjem.224.61

Correspondence: Katsunori Yanagihara, Department of Laboratory Medicine, Nagasaki University Graduate School of Biomedical Sciences, 1-7-1 Sakamoto, Nagasaki 852-8501, Japan.

e-mail: k-yanagi@nagasaki-u.ac.jp 


\section{Materials and Methods}

The medical records of 83 patients with MRSA bacteremia who had been admitted to Nagasaki University Hospital between January 2003 and December 2007 were retrospectively reviewed. All these patients with MRSA bacteremia were also retrospectively evaluated.

Age, sex, underlying disease, clinical features, presumed source, MRSA sensitivity, SCCmec types, virulence genes and prognosis were evaluated. In addition to these parameters, the subgroup of nonsurvivors of MRSA bacteremia was compared with that of survivors. Patients younger than 20 years of age were excluded from this study. If MRSA had been isolated on multiple occasions within a 5 -year period in the same patient, only the first episode of MRSA bacteremia was reviewed.

\section{Definition of bacteremia}

Bacteremia was defined as one or more positive blood cultures from patients with clinical signs of infection, such as fever, chills, and sweats, with or without local signs and symptoms. The presumed source of bacteremia was considered as the focus where symptoms and signs were present, or from which MRSA was isolated prior to the onset of bacteremia. Infection was considered to be catheter related when inflammatory signs were observed at the catheter insertion point or when the catheter culture was positive for MRSA (Gomez et al. 2007). The diagnosis of MRSA pneumonia was defined as follows: MRSA proven or suspected from a specimen of sputum, bronchoalveolar lavage or transthoracic aspiration, taken before initation of treatment, and chest X-ray consistent with the diagnosis of pneumonia. Signs and synptoms included two more of following: cough, purulent sputum, abnormal ausculatory findings, signs of respiratory failure, signs of dyspnea, and worsening of tracheal aspirate fluid in mechanically ventilated patients. One of the following was required: white blood cell count $(\mathrm{WBC}=$ leukocyte count) $>10,000 / \mu \mathrm{l}$, or $<4,500 / \mu \mathrm{l}$, band neutrophils $>15 \%$, pulse rate $>120$ beats/min or systolic hypotension (Kohno et al. 2007).

\section{Assessment of laboratory data}

Body temperature, WBC and C-reactive protein (CRP) on the day the initial blood culture gave a positive result were recorded. One of the 83 patients was not assessed on that day. Leucopenia was defined as a leukocyte count $<4,000 / \mu 1$. Severity of illness was assessed by the Sequential Organ Failure Assessment (SOFA) score (Vincent et al. 1996).

\section{Identification of bacteria}

All Staphylococcus aureus isolates were identified by colony morphologic analysis, Gram staining and catalase and coagulase tests. Isolates were identified as MRSA if the minimum inhibitory concentration (MIC) of oxacillin was $\geq 4 \mu \mathrm{g} / \mathrm{ml}$. The MICs of vancomycin (VCM), teicoplanin (TEIC), arbekacin (ABK), and linezolid (LZD) were determined using a dilution antimicrobial susceptibility test, according to the manufacturer's instructions (Eiken Chemical, Japan). All plates were incubated at $35^{\circ} \mathrm{C}$ for $24 \mathrm{~h}$.

\section{Antimicrobial treatment}

The exact design of the initial antimicrobial treatment regimen was the responsibility of the physician. The first antibiotic used was changed only in the case of clinical non-response to treatment or in the case of side effects.

\section{Real-time PCR assay}

The extraction of DNA and real-time PCR were performed as described previously (Motoshima et al. 2010). Bacterial DNA was extracted using Chelex (Bio-Rad Laboratories, Hercules, CA, USA), methanol, and boiling methods. PCR was performed using a LightCycler 480(Roche Applied Science, Mannheim, Germany) to amplify a total 10 genes in the same run. The PCR assay targeted $\mathrm{SCCmec}$ types I - IV, nuc, mecA, vanA, enterotoxinC (sec), toxic shock syndrome toxin (tsst), exfoliative toxin type b (etb), and lukS/ F-PV $(p v l)$. For SCCmec typing, three gene elements were used, SCCmec I, SCCmec II - III, SCCmec I - II - IV. The only four types of the eight known SCCmec types were detected in this study because SCCmec types V - VIII are not spread in Japan. The original PCR primers and probes were designed based on published primers (Johnson et al. 1991; Zhang et al. 2004), and sequential specificity was confirmed against all available data for genes in the Genbank database. All primers and probes were purchased from Nihon Gene Reserach Laboratories Inc. (Miyagi, Japan). The target probes for SCCmec I - II - IV, mecA, vanA, tsst, and pvl were labeled at the 5'end with FAM, and target probes for SCCmec I, SCCmec II - III, nuc, $e t b$, and $s e c$ were labeled at the $5^{\prime}$ - end with LCRED 610. Both sets of probes were labeled at the $3^{\prime}$-end with Black Hole Quencher (BHQ). Reactions conditions were $95^{\circ} \mathrm{C}$ for $10 \mathrm{~min}$ for activation of Taq polymerase, followed by 35 cycle $10 \mathrm{~s}$ at $96^{\circ} \mathrm{C}$ (denaturation) and $50 \mathrm{~s}$ at $60^{\circ} \mathrm{C}$ (annealing and extension). Continuous fluorescence was monitored at $483-533 \mathrm{~nm}$ (FAM) and 550-610 nm (LCRED610). Fluorescence data were analyzed using LightCycler480R Software version 1.5.

\section{Statistical analysis}

Patient characteristics and outcomes were compared survivors and nonsurvivors using Microsoft Excel 2007 for Windows. The $\chi^{2}$ test was used univariate comparison of categorical data. Variables with a $P$ value $<0.20$ in the univariate analyses were considered for inclusion in forward stepwise multivariate logistic regression to determine predictors associated with mortality for patients with MRSA bacteremia. A $P$ value less than 0.05 denoted the presence of a statistically significant difference.

\section{Results}

\section{Clinical characteristics and laboratory findings}

The clinical characteristics and laboratory findings of 83 patients with MRSA bacteremia are summarized in Table 1. These 83 patients with MRSA bacteremia comprised 44 men and 39 women with the mean age of 63.7 years (Table1) and mode age range of 70 to 79 years. The mean body temperature was $38.8^{\circ} \mathrm{C}$. The mean leukocyte count and the CRP values were $11,120 / \mu \mathrm{l}$ and $12.3 \mathrm{mg} / \mathrm{dl}$, respectively. Of the 83 patients, $30(36.1 \%)$ had malignancy and 25 (30.1\%) had received immunosuppressive drugs. Many patients had at least 2 comorbid conditions, such as malignancy and diabetes mellitus (Table 1). There were 15 cases $(18.1 \%)$ of intravascular catheter-related problems. Pneumonia was the presumed source of MRSA bacteremia in 14 patients $(16.9 \%)$, while 12 patients $(14.5 \%)$ suffered from bacteremia after an operation (Table 2). 


\section{Treatment}

Of the 83 patients, $22(26.5 \%)$ were treated with VCM as first line therapy, $33(39.8 \%)$ with TEIC, $3(3.6 \%)$ with ABK, $11(13.3 \%)$ with LZD and 11 with other antibiotics (such as rifampicin or minocycline). The VCM trough level was measured $54.5 \%(12 / 22)$. The mean age, body temperature and laboratory data did not differ significantly between patients treated with different antibiotics. The $\mathrm{MIC}_{90}$ values of VCM, TEIC, ABK and LZD were 1, 0.75, 0.75 and 2, respectively. Most of the isolates obtained from blood culture were sensitive to these four antibiotics (Fig. $1)$.

Table 1. Clinical characteristics and laboratory findings of patients with MRSA bacteremia.

\begin{tabular}{lc}
\hline Sex (male/female) & $44 / 39$ \\
Mean age (years) & $63.7 \pm 17.0$ \\
\hline Underlying disease: & \\
Malignancy & $30(36.1 \%)$ \\
Cardiovascular disease & $26(31.3 \%)$ \\
Immunosupressive drug or corticosteroid use & $25(30.1 \%)$ \\
Diabetes mellitus & $22(26.5 \%)$ \\
Digestive disease & $19(22.9 \%)$ \\
Chronic renal failure & $15(18.1 \%)$ \\
Central nervous system disease & $11(13.3 \%)$ \\
Transplantation & $11(13.3 \%)$ \\
Respiratory disease & $10(12.0 \%)$ \\
Autoimmune $/$ allergic disease & $8(9.6 \%)$ \\
Others & $10(12.0 \%)$ \\
Body temperature $\left({ }^{\circ} \mathrm{C}\right)^{\mathrm{a}}$ & $38.8 \pm 1.0$ \\
Leukocyte count $(/ \mu \mathrm{l})^{\mathrm{a}}$ & $11,119.5+7,906.7$ \\
CRP $(\mathrm{mg} / \mathrm{ml})^{\mathrm{a}}$ & $12.3 \pm 8.1$ \\
\hline
\end{tabular}

${ }^{a}$ Data are the mean \pm S.D.

\section{Genetic analysis}

The results of SCCmec and virulence genes are shown in Fig. 2. Among the 83 isolates obtained from blood culture, 77 isolates could be analyzed. The isolates from 61 patients $(79.2 \%)$ were identified as carrying SCCmec type II and $14(18.2 \%)$ were identified as carrying type IV. In virulence genes, 61 isolates $(79.2 \%)$ were tsst positive and 59 isolates (76.6\%) sec positive. A total of $90.2 \%$ of type II (55/61) and $28.6 \%$ of typeIV (4/14) isolates had tsst and sec genes. No isolates were $e t b$ and $p v l$ positive in this study.

\section{Prognosis}

Table 3 shows the univariate analyses of predictors associated with mortality for patients with MRSA bacteremia. The mortality rate is $39.8 \%(33 / 83)$ in this study. The male-to-female ratio, mean age, and body temperature did not differ between survivors and nonsurvivors. In nonsurvivors, the leukocyte count was slightly lower and the CRP level was slightly higher than in survivors, although the dif-

Table 2. Presumed source of infection in patients with MRSA bacteremia.

\begin{tabular}{lc}
\hline & No. of patients (\%) \\
\hline Intravascular device & $15(18.1 \%)$ \\
Respiratory tract & $14(16.9 \%)$ \\
Abdominal cavity $^{\mathrm{a}}$ & $6(7.2 \%)$ \\
Bone $^{\mathrm{a}}$ & $6(7.2 \%)$ \\
Soft tissure $^{\mathrm{a}}$ & $5(6.0 \%)$ \\
Articulus $^{\mathrm{a}}$ & $5(6.0 \%)$ \\
Mediastium $^{\mathrm{a}}$ & $4(4.6 \%)$ \\
Others & $6(7.2 \%)$ \\
Unknown & $22(26.5 \%)$ \\
\hline
\end{tabular}

${ }^{a}$ Twelve patients had infection at a surgical site.

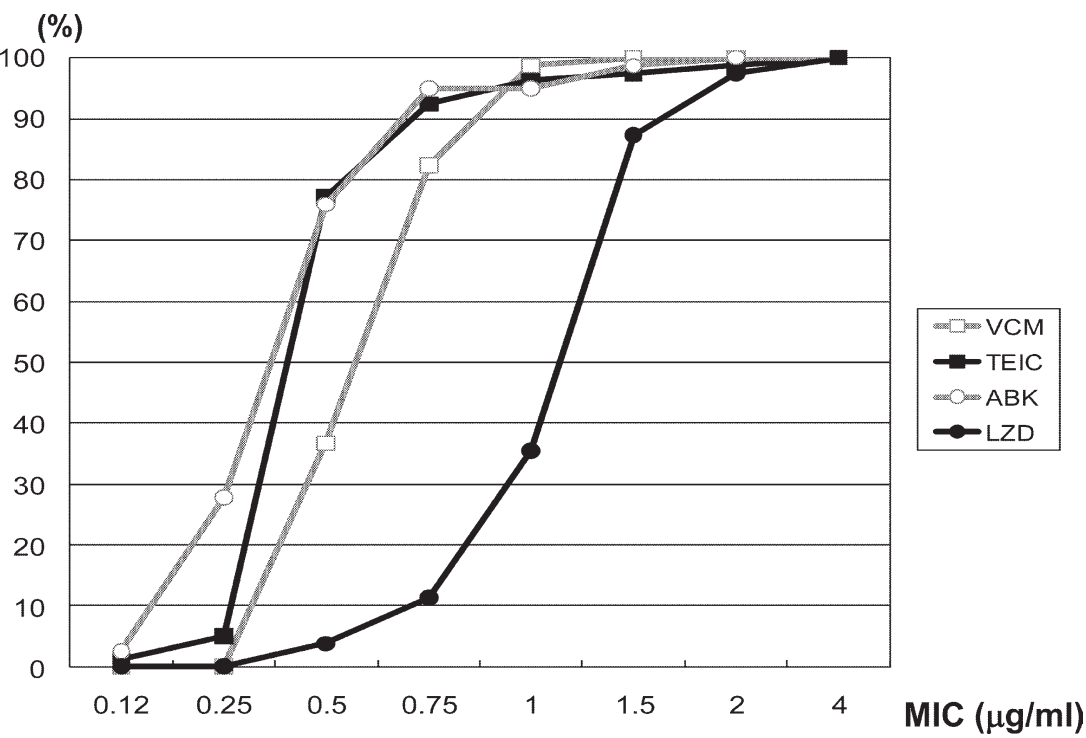

Fig. 1. Cumulative minimum inhibitory concentration curves in patients with MRSA bacteremia. The $\mathrm{MIC}_{90}$ values of VCM, TEIC, ABK and LZD were 1, 0.75, 0.75 and 2, respectively. 
(a)

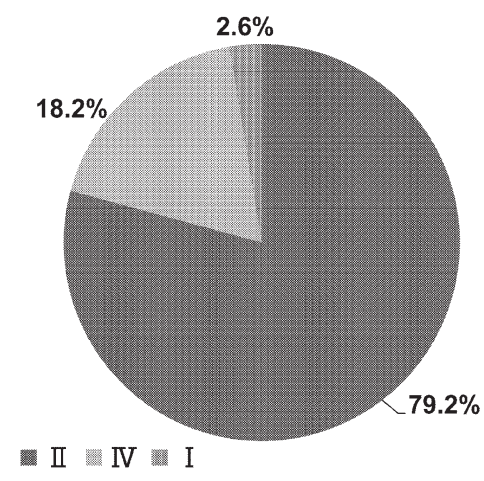

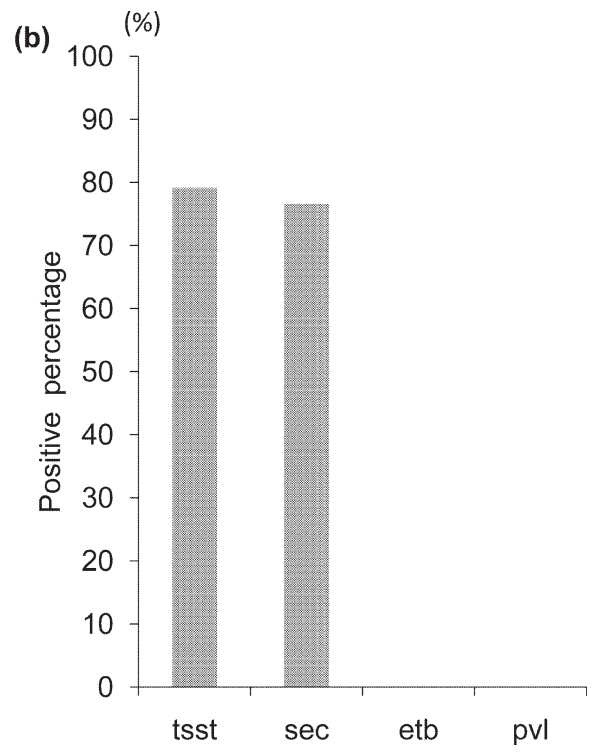

Fig. 2. SCCmec types and virulence genes in patients with MRSA bacteremia. Shown are SCCmec types (a) and virulence genes (b) in patients with MRSA bacteremia. The isolates from 61 patients (79.2\%) were identified as carrying SCCmec type II and 14 (18.2\%) were identified as carrying type IV.

Table 3. Univariate analyses of predictors associated with mortality for patients with MRSA bacteremia.

\begin{tabular}{llc}
\hline \multicolumn{1}{c}{ Predictor } & \multicolumn{1}{c}{ OR $(95 \% \mathrm{CI})$} & $P$ value \\
\hline Male gender & $0.73(0.30-1.79)$ & 0.510 \\
Age $\geq 70$ & $0.90(0.37-2.18)$ & 1.000 \\
Malignancy & $1.56(0.63-3.89)$ & 0.360 \\
Cardiovascular disease & $1.17(0.45-3.00)$ & 0.810 \\
Immunosupressive drug or corticosteroid use & $2.61(0.99-6.83)$ & 0.050 \\
Diabetes mellitus & $0.62(0.22-1.76)$ & 0.450 \\
Digestive disease & $0.63(0.21-1.88)$ & 0.440 \\
Chronic renal failure & $1.01(0.32-3.17)$ & 1.000 \\
Central nervous system disease & $0.53(0.13-2.14)$ & 0.510 \\
Transplantation & $9.00(1.80-44.96)$ & 0.006 \\
Respiratory disease & $0.43(0.42-6.05)$ & 0.510 \\
Autoimmune/allergic disease & $0.90(0.20-4.05)$ & 0.810 \\
Catheter related infection & $0.49(0.14-1.69)$ & 0.380 \\
Pneumonia & $7.83(1.98-30.93)$ & 0.002 \\
Fever $\geq 39^{\circ} \mathrm{C}$ & $0.54(0.22-1.35)$ & 0.250 \\
Leukocyte count $<4,000 / \mu \mathrm{l}$ & $5.22(1.27-21.50)$ & 0.020 \\
CRP $\geq 20$ mg/dl & $1.72(0.54-5.47)$ & 0.380 \\
SOFA score $\geq 10$ & $4.84(1.48-15.78)$ & 0.009 \\
Treatment with VCM & $2.96(1.08-8.08)$ & 0.040 \\
MIC of VCM $\geq 1 \mu \mathrm{g} / \mathrm{ml}$ & $1.06(0.33-3.39)$ & 1.000 \\
SCCmec type II & $0.89(0.29-2.71)$ & 1.000 \\
tsst gene negative & $1.54(0.51-4.66)$ & 0.570 \\
sec gene negative & $2.10(0.72-6.12)$ & 0.180 \\
\hline
\end{tabular}

ferences were not significant. However, cases with a leukocyte count lower than baseline $(<4,000 / \mu 1)$ had a higher mortality $(8 / 11: 72.7 \%)$ than those with a leukocyte count $\geq$ 4,000/ $\mu 1(24 / 71: 33.8 \%)(P=0.02)$. In contrast, there was no difference between patients with high ( $\geq 20 \mathrm{mg} / \mathrm{dl})$ and low $(<20 \mathrm{mg} / \mathrm{dl}) \mathrm{CRP}$ with regards to mortality. The mortality of SOFA score $\geq 10$ was higher $(P=0.009)$. In underlying diseases, transplantation was a predictor associ- 
Table 4. Multivariate analyses of predictors associated with mortality for patients with MRSA bacteremia.

\begin{tabular}{lcc}
\hline \multicolumn{1}{c}{ Predictor } & OR $(95 \% \mathrm{CI})$ & $P$ value \\
\hline Pneumonia & $6.20(1.41-27.25)$ & 0.016 \\
Transplantation & $7.47(1.36-40.96)$ & 0.021 \\
SOFA score $\geq 10$ & ND & ND \\
Leukocyte count $<4,000 / \mu 1$ & ND & ND \\
Treatment with VCM & $3.22(1.06-9.80)$ & 0.039 \\
sec gene negative & ND & ND \\
\hline
\end{tabular}

ND: not detected

ated with mortality $(P=0.006)$. Pneumonia was associated with mortality $(P=0.002)$. The mortality of patients treated with VCM as first line was 59.1\% (13/22) and significantly higher than those of other treatments (TEIC: 33.3\%; ABK: 0\%; LZD: $27.2 \%)(P=0.04)$. We did not detect any correlation between the trough level and mortality. VCM MIC $\geq 1 \mu \mathrm{g} / \mathrm{ml}$ was not a predictor associated with mortality. In genetic analyses, SCCmec types and virulence genes had no relations with mortality.

Independent predictors associated with mortality in the multivariate analyses were pneumonia $(P=0.016)$, treatment with $\operatorname{VCM}(P=0.039)$, and transplantation $(P=0.021)$ (Table 4$)$. The mortality of patients who had pneumonia and VCM treatment was $100 \%(4 / 4)$.

\section{Discussion}

Bacteremia caused by MRSA is one of the most serious problems among infectious diseases, annually resulting in significant morbidity and mortality. Thus it is very important to assess the clinical characteristics of MRSA bacteremia and to evaluate predictors of mortality in patients with MRSA bacteremia for appropriate treatments. In the present study, we investigated the underlying disease, presumed source, MRSA sensitivity to antibiotics, antibiotic choice and prognosis of patients with MRSA.

Many of the patients with MRSA bacteremia had malignancy, cardiovascular disease, immunosuppressive illness, and diabetes mellitus, which is similar to the findings of other reports (Hidayat et al. 2006; Gomez et al. 2007; Silvestre et al. 2009). Both our study and other clinical investigations (Gomez et al. 2007; Silvestre et al. 2009) have shown that intravascular devices, lower respiratory tract infections and surgical site infections cause MRSA bacteremia, suggesting the importance of prophylaxis. The mortality of MRSA bacteremia determined in this study $(39.8 \%)$ was also similar to those reported previously (Gomez et al. 2007; Laupland et al. 2008). The prognosis of MRSA bacteremia in transplant recipients was significantly worse in multivariate analyses (Table 4). Our hospital conducts both liver and bone marrow transplantations. A previous study suggested that organ transplantation is one of the risk factors for MRSA bacteremia (Laupland et al. 2008). The present study is the first report to describe a relationship between transplantation and the mortality of MRSA bacteremia. It is difficult to recognize infection in transplant recipients, since signs and symptoms are often diminished (Fishman 2007), while many risk factors including operative stress and immunosuppressive drug use in transplant recipients are major concerns. These factors may be the causes of the poor prognosis of MRSA in transplant recipients.

In our study, cases with a leukocyte count lower than $4,000 / \mu 1$ had a higher mortality in univariate analyses (Table3). A previous study suggested that neutropenia is a factor that contributes to hospital-acquired bacteremia (Yoshida et al. 2005). However, there have been no reports describing the relationship between leucopenia and the mortality of MRSA bacteremia. Leucopenia is one of the diagnostic criteria of Acute Physiology and Chronic Health Evaluation (APACHE) II score (Knaus et al. 1985) and Systemic Inflammatory Response Syndrome (SIRS) (Bone et al. 1992), and therefore may be a good prognostic marker in MRSA bacteremia.

In a recent study, the rate of recovery in patients with MRSA bacteremia at VCM MIC of $\leq 0.5 \mu \mathrm{g} / \mathrm{ml}$ was about $55.6 \%$, yet this recovery rate fell to $9.5 \%$ at a MIC of $1-2$ $\mu \mathrm{g} / \mathrm{ml}$ (Sakoulas et al. 2004). Furthermore, patients with high MIC $(\geq 2)$ have poorer treatment responses and higher infection-related mortality (Hidayat et al. 2006). Our results found no reduction in the sensitivity to antibiotics including VCM and no relationship between antibiotic MIC and mortality.

In Japan, about $4 \%$ of MRSA clones are classified as SCCmec type IV (Chongtrakool et al. 2006; Zaraket et al. 2007). However, in our study, isolates from 61 patients (79.2\%) were identified as carrying SCCmec type II and $14(18.2 \%)$ were identified as carrying type IV. As it has been reported that community acquired (CA) - MRSA was brought into hospitals from the community (Zaraket et al. 2007), SCCmec type IV might be also brought into and spread throughout our hospital. Ganga et al. (2009) has been reported that SCCmec II was a prognostic factor of MRSA bacteremia. In contrast, our study indicated that SCCmec types and virulence gene had not been associated with prognosis. Additional studies are needed to decide whether SCCmec and virulence genes influence the outcome of MRSA bacteremia.

In multivariate analyses, pneumonia as a source and treatment with VCM were independent predictors associated with mortality (Table 4). Previous studies reported that pneumonia is one of the prognostic factors of MRSA bacteremia (Gould 2007; Wang et al. 2010). This reason may be due to the difficulty of the diagnosis of MRSA pneumonia, the high mortality of only MRSA pneumonia or the inadequate effectiveness of glycopeptides such as VCM and TEIC (Rello et al. 2005). Stevens et al. (2002) reported that the efficacy of VCM in patients with MRSA bacteremia was equal to that of LZD. In contrast, Wunderink et al. (2003) reported that the efficacy of LZD was higher than 
that of VCM. In our study, it is possible that the worse prognosis of VCM treatment was due to lower VCM trough (in most cases $5-10 \mu \mathrm{g} / \mathrm{ml}$ ) than recommended trough of 15-20 $\mu \mathrm{g} / \mathrm{ml}$ (Rybak et al. 2009). However, some studies showed no correlation between the VCM trough level and prognosis (Hidayat et al. 2006; Musta et al. 2009). Our study was similar to these reports. Thus, the lower efficacy of VCM for MRSA bacteremia remains inconclusive. However, our data suggest that other treatments should be choiced if the primary focus of MRSA bacteremia is pneumonia, considered poor tissue penetration in the lung (Kollef 2007).

In conclusion, our study showed similar mortality of MRSA bacteremia as reported previously. Immunosuppressive illness was associated with morbidity and mortality. Most of the MRSA isolates obtained from blood culture was sensitive to four antibiotics tested and there was no relationship between MIC and mortality. When the primary focus of MRSA bacteremia is pneumonia, other antibiotics rather than VCM should be choiced, even if the MRSA sensitivity to antibiotics is good.

\section{Conflict of Interest}

The authors report no conflict of interest.

\section{References}

Bone, R.C., Balk, R.A., Cerra, F.B., Dellinder, R.P., Fein, A.M., Knaus, W.A., Schein, R.M. \& Sibbald, W.J. (1992) Definition for sepsis organ failure and guideline for the use of innovative therapies in sepsis. Chest, 101, 1644-1655.

Chongtrakool, P., Ito, T., Ma, X.X., Kondo, Y., Trakulsomboon, S., Tiensasitorm, C., Jamklang, M., Chavalit, T., Song, J.H. \& Hiramatsu, K. (2006) Staphylococcal cassette chromosome mec (SCCmec) typing of methicillin-resistant Staphylococcus aureus strains isolated in 11 Asian countries: a proposal for a new nomenclature for SCCmec elements. Antimicrob. Agents Chemother, 50, 1001-1012.

Cosgrove, S.E., Sakoulas, G., Perencevich, E.N., Schwaber, M.J., Karchmer, A.W. \& Carmeli,Y. (2003) Comparison of mortality associated with methicillin-resistant and methicillinsusceptible Staphylococcus aureus bacteremia: a meta-analysis. Clin. Infect. Dis., 36, 53-59.

Fishman, J.A. (2007) Infection in solid-organ transplant recipients. N. Engl. J. Med., 357, 2601-2614.

Ganga, R., Riederer, K., Sharma, M., Fakih, M.G., Johnson, L.B., Shemes, S. \& Khatib, R. (2009) Role of SCCmec type in outcome of Staphylococcus aureus bacteremia in a single medical center. J. Clin. Microbiol., 47, 590-595.

Gomez, J., Garcia, E., Banos, R., Ganteras, M., Ruiz, J., Bamos, V., Herrero, J.A. \& Valdes, M. (2007) Predictors of mortality in patients with methicillin-resistant Staphylococcus aureus (MRSA) bacteremia: the role of empiric antibiotic therapy. Eur. J. Clin. Microbiol. Infect. Dis., 26, 239-245.

Gould, I.M. (2007) MRSA bacteremia. Int. J. Antimicrob. Agents, 30 (Suppl 1), S66-S70.

Hidayat, L.K., Hsu, D.I., Quist, R., Shriner, K.A. \& WongBeringer, A. (2006) High dose vancomycin therapy for methicillin-resistant Staphylococcus aureus infections. Arch. Intern. Med., 166, 2138-2144.

Johnson, W.M., Tyler, S.D., Ewan, E.P., Ashton, F.E., Pollard, D.R. \& Rozee, K.R. (1991) Detection of genes for enterotoxins, exfoliative toxins, and toxic shock syndrome toxin 1 in Staph- ylococcus aureus by the polymerase chain reaction. J. Clin. Microbiol., 29, 426-430.

Knaus, W.A., Draper, E.A., Wagner, D.P. \& Zimmerman, J.E., (1985) APACHE II : a severerity of disease classification system. Crit. Care Med., 13, 818-829.

Kohno, S., Yamaguchi, K., Aikawa, N., Sumiyama, Y., Odagiri, S., Aoki, N., Niki, Y., Watanabe, S., Furue, M., Ito, T., CrossDabrera, R. \& Tack, K.J. (2007) Linezold versus Vancomycin for the treatment of infections caused by methicillin resistant Staphylococcus aureus in Japan. J. Antimicrob. Chemother., 60, 1361-1369.

Kollef, M.H. (2007) Limitations of vancomycin in the management of resistant staphylococcal infections. Clin. Infect. Dis., 45 (Suppl 3), S191-195.

Laupland, K.B., Ross, T. \& Gregson, D.B. (2008) Staphylococcus aureus bloodstream infections: risk factors, outcomes, and the influence of methicillin resistance in Calgary, Canada, 20002006. J. Infect. Dis., 198, 336-343.

Leibovici, L., Shraga, I., Drucker, M., Konigsberger, H., Samra, Z. \& Pitlik S.D. (1998) The benefit of appropriate empirical antibiotic treatment in patients with bloodstream infection. $J$. Intern. Med., 244, 379-386.

Mizushima, Y., Kawasaki, A. \& Hirata, H. (1994) An analysis of bacteremia in a university hospital in Japan over a 10-year period. J. Hosp. Infect., 27, 285-298.

Motoshima, M., Yanagihara, K., Morinaga, Y., Matsuda, J., Yamada, Y., Kohno, S. \& Kamihira, S. (2010) Genetic diagnosis of community-acquired MRSA: a multiplex real-time PCR method for staphylococcal cassette chromosome mec typing and detecting toxin genes. Tohoku J. Exp. Med., 220, 165-170.

Musta, A.C., Riederer, K., Shemes, S., Chase, P., Jose, J., Johnson, L.B. \& Khatib, R. (2009) Vancomycin MIC plus heteroresistance and outcome of methicillin-resistant Staphylococcus aureus bacteremia: trends over 11 years. J. Clin. Microbiol., 47, 1640-1644.

Rello, J., Sole-Violan, J., Sa-Borges, M., Gamacho-Montero, J., Munos, E., Sirgo, G., Olona, M. \& Diaz, E. (2005) Pneumonia caused by oxacillin resistant Staphylococcus aureus treated with glycopeptides. Crit. Care Med., 33, 1983-1987.

Rybak, M.J., Lomaestro, B.M., Rotschafer, J.C., Moellering, R.C., Craig, W.A., Billeter, M., Dalovisio, J.R. \& Levine, D.P. (2009) Vancomycin therapeutic guidelines: a summary of consensus recommendations from the Infectious Disease Society of America, the American Society of Health-System Pharmacists, and the Society of Infectious Diseases Pharmacists. Clin. Infect. Dis., 49, 325-327.

Sakoulas, G., Moise-Broder, P.A., Schentag, J., Forrest, A., Moellering, R.C. Jr. \& Eliopoulos, G.M. (2004) Relationship of MIC and bacterial activity to efficacy of vancomycin for treatment of methicillin-resistant Staphylococcus aureus bacteremia. J. Clin. Microbiol., 42, 2398-2402.

Selvey, L., Whitby, M. \& Johnson, B. (2000) Nosocomial methicillin-resistant $S$. aureus bacteremia: is it any worse than nosocomial methicillin-sensitive $S$. aureus bacteremia? Infect. Control Hosp. Epidemiol., 21, 645-648.

Silvestre, J., Povoa, P., Coelho, L., Almeida, E., Moreira, P., Femandes, A., Mealha, R. \& Sabino, H. (2009) Is C-reactive protein a good prognostic marker in septic patients? Intensive Care Med., 35, 909-913.

Stevens, D.L., Herr, D., Lampiris, H., Hunt, J.L., Batts, D.H. \& Hafkin, B. (2002) Linezolid versus vancomycin for the treatment of methicillin-resistant Staphylococcus aureus infections. Clin. Infect. Dis., 34, 1481-1490.

Tiemersma, E.W., Bronzwaer, S.L., Lyytikainen, O., Degener, L.E., Schrijnemakers, P., Bruinsma, N., Monen, J., Witte, W. \& Grundman, H.; Antimicrobial Resistance Surveillance System Participants. (2004) Methicillin-resistant S. aureus in Europe, 1999-2002. Emerg. Infect. Dis., 10, 1627-1634. 
Vincent, J.L., Moreno, R., Takala, J., Willatts, S., De Mendonca, A., Bruining, H., Reinhart, C.K., Suter, P.M. \& Thijs, L.G. (1996) The SOFA (Sepsis-related Organ Failure Assessment) score to describe organ dysfunction/failure. On beharf of the Working Group on Sepsis-Related Problems of the European Society of Intensive Care Medline. Intensive Care Med., 22, 707-710.

Wang, J.L., Wang, J.T., Sheng, W.H., Chen, Y.C. \& Chang, S.C. (2010) Nosocominal methicillin-resistant Staphylococcus aureus (MRSA) bacteremia in Taiwan: mortality analyses and the impact of vancomycin, $\mathrm{MIC}=2 \mathrm{mg} / \mathrm{L}$, by the broth microdilution method. BMJ Infect. Dis., 10, 159.

Wisplinghooff, H., Bischoff, T., Tallent, S.M., Seifert, H., Wenzei, R.P. \& Edmond, M.B. (2004) Nosocomial bloodstream infections in US hospitals: analysis of 24,179 cases from a prospective nationwide surveillance study. Clin. Infect. Dis., 39, 309-317.

Wunderink, R.G., Rello, J., Cammarata, S.K., Croos-Dabrera, R.V. \& Kollef, M.H. (2003) Linezolid vs vancomycin: analysis of two double-blind studies of patients with methicillin-resistant Staphylococcus aureus nosocomial pneumonia. Chest, 124, 1789-1797.

Yoshida, T., Tsushima, K., Tsuchiya, A., Nishikawa, N., Shirahata, K., Kaneko, K., Ito, K., Kawakami, H., Nakagawa, S., Suzuki, T., Kubo, K. \& Ikeda, S. (2005) Risk factors for hospitalacquired bacteremia. Interm. Med., 44, 1157-1162.

Zaraket, H., Otsuka, T., Saito, K., Dohmae, S., Takeno, T., Higuchi, W., Ohkubo, T., Ozaki, K., Takano, M., Reva, I., Baranovich, T. \& Yamamoto, T. (2007) Molecular characterization of methicillin-resistant Staphylococcus aureus in hospitals in Niigata, Japan: divergence and transmission. Microbiol. Immunol., 151, 171-176.

Zhang, K., Sparling, J., Chow, B.L., Elsayed, S., Hussain, Z., Church, D.L., Gregson, D.B., Louie, T. \& Conly, J.M. (2004) New quadriplex PCR assay for detection of methicillin and mupirocin resistance and simultaneous discrimination of Staphylococcus aureus from coagulase-negative staphylococci. J. Clin. Microbiol., 42, 4947-4955. 